\title{
Comparison of 4-French versus 5-French sheaths for diagnostic coronary angiography via the snuffbox approach
}

\author{
Ji Woong Roh ${ }^{1}$, Hee-Yeol Kim ${ }^{1}$, Youngkeun Ahn' ${ }^{2}$, Myung Ho Jeong², Yongcheol Kim² \\ ${ }^{1}$ Department of Cardiology, Bucheon St. Mary's Hospital, \\ The Catholic University College of Medicine, Seoul, Republic of Korea \\ ${ }^{2}$ Department of Cardiology, Chonnam National University Hospital, Gwangju, Republic of Korea
}

\begin{abstract}
Background: Although a shorter hemostasis duration would be expected when compared with the conventional radial approach as the diameter of the distal radial artery is smaller than that of the conventional radial artery, the optimal duration of hemostasis in diagnostic coronary angiography (CAG) via the distal radial approach, termed the snuffbox approach, has not been well investigated.

Methods: Data from 171 patients were retrospectively collected (55 and 116 patients in the 4-French [Fr] and 5-Fr sheath groups, respectively). The patients had suspected myocardial ischemia and were undergoing diagnostic CAG via the snuffbox approach at a single center between January 2019 and August 2019.

Results: The mean age of the study population was $67.6 \pm 11.0$ years, and $69 \%$ were male. The left snuffbox approach was performed in 146 (85.4\%) patients. The mean snuffbox puncture time, defined as the time interval between local anesthesia and sheath cannulation, was $145.1 \pm 120.8 \mathrm{~s}$. The hemostasis duration was significantly shorter in the 4-Fr sheath group than in the 5-Fr sheath group (70 [62-90] vs. 120 [120-130] min; $p<0.001)$. There were local hematomas, defined as $\leq 5 \mathrm{~cm}$ in diameter, at the puncture site in 8 (4.7\%) patients. Moreover, there were no conventional and distal radial artery occlusions, assessed by manual pulse, after hemostasis in the study population during hospitalization. Conclusions: Successful hemostasis was obtained within 2 h for diagnostic CAG via the snuffbox approach using the 4-Fr or 5-Fr sheaths. (Cardiol J 2021; 28, 4: 528-533)
\end{abstract}

Key words: coronary angiography, coronary catheterization, hemostasis, radial artery

\section{Introduction}

The conventional radial artery approach in coronary angiography $(\mathrm{CAG})$ is currently preferred due to several advantages (e.g., reduced vascular complications, patient comfort, and early ambulation) when compared with the femoral approach [1-3]. Because of these advantages, it is recommended as the first and standard approach for CAG and percutaneous coronary intervention (PCI) in the current guidelines [4]. However, radial artery occlusion remains the most common local vascular complication, with a reported incidence of between $0.8 \%$ and $30 \%$ [5]. Furthermore, significant accesssite complications, including pseudoaneurysm and arteriovenous fistulas, which occasionally require surgery or transfusions, cannot be avoided [6].

Recently, the distal radial approach, termed the snuffbox approach, has gained the interest of interventional cardiologists because it may have fewer complications than the conventional radial artery approach. The feasibility of the snuffbox

Address for correspondence: Yongcheol Kim, MD, Department of Cardiology, Chonnam National University Hospital, 42 Jebong-ro, Dong-gu, Gwangju 61469, Republic of Korea, tel: 82-62-220-6246, fax: 82-62-223-3105,

e-mail: Dr.YongcheolKim@gmail.com

Received: 6.11.2019 Accepted: 15.12.2019

This article is available in open access under Creative Common Attribution-Non-Commercial-No Derivatives 4.0 International (CC BY-NC-ND 4.0) license, allowing to download articles and share them with others as long as they credit the authors and the publisher, but without permission to change them in any way or use them commercially. 
approach for coronary catheterization has been demonstrated in several studies, showing potential benefits in terms of less bleeding and few accesssite complications [7-14]. With respect to hemostasis in the snuffbox approach, a shorter hemostasis duration would be expected compared with the conventional radial approach as the diameter of the distal radial artery is significantly smaller than that of the conventional radial artery [15, 16]. However, the optimal duration for hemostasis after CAG via the snuffbox approach has not been well investigated. Therefore, the aim of the study was to investigate the hemostasis duration after diagnostic CAG via the snuffbox approach using either a 4-French (Fr) or 5-Fr sheath.

\section{Methods}

Data was collected retrospectively from patients with suspected myocardial ischemia, at a single center, who underwent diagnostic CAG via the snuffbox approach between January 2019 and August 2019. A single operator (Y.K.) attempted the snuffbox approach in patients who had a well-palpable pulse in the anatomical snuffbox area. The study protocol was approved by the institutional review board of Chonnam National University Hospital (approval number: CNUH-2019-280), who waived the requirement for informed consent owing to the retrospective observational study design.

Local anesthesia was achieved through a $1-\mathrm{mL}$ lidocaine hydrochloride injection into an anatomical snuffbox with a 26 -gauge needle. Thereafter, puncture was performed using a 21-gauge open needle using the anterior wall puncture technique. After a successful puncture, a 0.018 -inch hair wire was inserted; this was followed by the insertion of a 4-Fr or 5-Fr radial sheath (Prelude Radial ${ }^{\circledR}$; Merit Medical, UT, USA). The selection of the sheath size was left at the physician's discretion. After successful sheath cannulation, a cocktail including $2.5 \mathrm{mg}$ of verapamil, $0.2 \mathrm{mg}$ of nitroglycerine, and 3000 units of unfractionated heparin was administered before catheterization in all patients. Hemostasis was obtained using a compressive bandage with gauze (Suppl. Video 1). A local hematoma was defined if the hematoma was $\leq 5 \mathrm{~cm}$ in diameter according to Early Discharge After Transradial Stenting of Coronary Arteries (EASY) classification I [17].

\section{Statistical analysis}

All categorical variables were presented as numbers with percentages and were analyzed using the $\chi^{2}$ test or Fisher exact test. Continuous variables were expressed as mean with standard deviation or median with interquartile ranges and were compared using the un-paired t-test or Mann-Whitney U test, as appropriate. Statistical analyses were conducted using $\mathrm{R}$ version 3.5.0 (R Foundation for Statistical Computing, Vienna, Austria) and SPSS 22.0 for Windows (SPSS-PC, Chicago, IL, USA).

\section{Results}

Between January 2019 and August 2019, there were a total of 474 consecutive patients who had planned to undergo CAG or PCI by single operator. Among them, cases of conventional radial or femoral approach, failed snuffbox punctures, failed CAG, PCI, and CAG using a 6 -Fr sheath were excluded. Therefore, a total of 171 patients were selected who underwent successful diagnostic CAG via the snuffbox approach using a 4-Fr $(n=55)$ or 5 - Fr sheath $(\mathrm{n}=116)$ (Fig. 1).

During the study period, the success rate with the snuffbox approach was $97.2 \%$ (380/391). Baseline clinical characteristics of the study population, including the 4-Fr and 5-Fr sheath groups, are shown in Table 1 . The mean age was $67.6 \pm$ \pm 11.0 years and $118(69.0 \%)$ patients were male. There were no differences in body mass index, systolic and diastolic blood pressure, hypertension, diabetes mellitus, chronic kidney disease, and periprocedural anti-thrombotic medication. The 5-Fr sheath group had a higher composition of male than the 4-Fr sheath group. The most common reason for CAG was a suspicious coronary artery disease (95.3\%).

The mean and median hemostasis durations were significantly shorter in the 4-Fr sheath group than the 5-Fr sheath group, as shown in Figure 2 (88.4 \pm 42.0 and 70 [62-90] $\mathrm{min}$ vs. $134.0 \pm 35.2$ and $120[120-130] \mathrm{min} ; \mathrm{p}<0.001)$. With respect to puncture-site complications, there were no conventional and distal radial artery occlusions, assessed by manual pulse, during hospitalization. Local hematomas occurred in $8(4.7 \%)$ cases, including 3 cases in the 4 -Fr group and 5 cases in the 5 -Fr group. There were no cases of puncture-related local numbness or major bleeding complications requiring surgery or transfusions, as shown in Table 2.

\section{Discussion}

In the present study, the median hemostasis durations were about $1 \mathrm{~h}$ and $2 \mathrm{~h}$ in the 4 -Fr and 


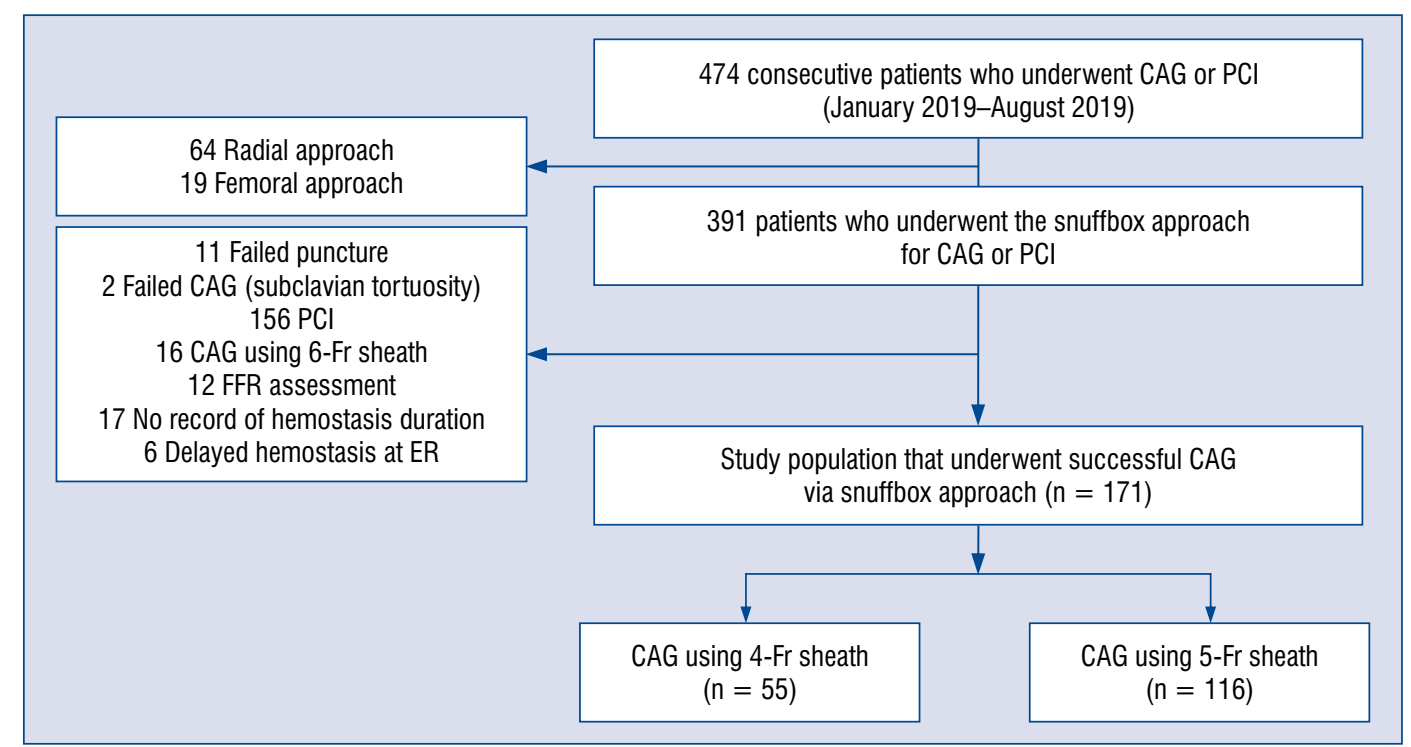

Figure 1. Study flow chart; CAG — coronary angiography; $\mathrm{PCl}$ - percutaneous coronary intervention; FFR — fractional flow reserve; ER - emergency room.

Table 1. Baseline clinical characteristics of the study population.

\begin{tabular}{|c|c|c|c|c|}
\hline Patients & Total $(n=171)$ & $4 \mathrm{Fr}(\mathrm{n}=55)$ & $5 \mathrm{Fr}(n=116)$ & $\mathbf{P}$ \\
\hline \multicolumn{5}{|l|}{ Demographics } \\
\hline Age [years] & $67.6 \pm 11.0$ & $68.0 \pm 10.3$ & $67.4 \pm 11.3$ & 0.752 \\
\hline Male & $118(69.0 \%)$ & $24(43.6 \%)$ & $94(81.0 \%)$ & $<0.001$ \\
\hline Body mass index $\left[\mathrm{kg} / \mathrm{m}^{2}\right]$ & $24.9 \pm 3.5$ & $24.5 \pm 4.1$ & $25.2 \pm 3.2$ & 0.345 \\
\hline \multicolumn{5}{|l|}{ Vital signs } \\
\hline SBP [mmHg] & $127.8 \pm 21.4$ & $129.6 \pm 21.2$ & $127.0 \pm 21.6$ & 0.462 \\
\hline $\mathrm{DBP}[\mathrm{mmHg}]$ & $76.2 \pm 14.2$ & $77.9 \pm 12.9$ & $75.4 \pm 14.8$ & 0.274 \\
\hline Heart rate $[\mathrm{bpm}]$ & $76.4 \pm 13.5$ & $79.3 \pm 13.1$ & $75.0 \pm 13.5$ & 0.055 \\
\hline \multicolumn{5}{|l|}{ Risk factors } \\
\hline Hypertension & $130(76.0 \%)$ & $37(67.3 \%)$ & $93(80.2 \%)$ & 0.098 \\
\hline Diabetes mellitus & $52(30.4 \%)$ & $14(25.5 \%)$ & $38(32.8 \%)$ & 0.428 \\
\hline Dyslipidemia & $102(59.6 \%)$ & $29(52.7 \%)$ & $73(62.9 \%)$ & 0.270 \\
\hline Current smoking & $27(15.8 \%)$ & $6(10.9 \%)$ & $21(18.1 \%)$ & 0.327 \\
\hline CKD $\left(\right.$ eGFR $\left.<60 \mathrm{~mL} / \mathrm{min} / 1.73 \mathrm{~m}^{2}\right)$ & $42(24.6 \%)$ & $12(21.8 \%)$ & $30(25.9 \%)$ & 0.701 \\
\hline \multicolumn{5}{|l|}{ Laboratory findings } \\
\hline Hemoglobin [g/dL] & $13.0 \pm 2.0$ & $12.7 \pm 1.9$ & $13.1 \pm 2.1$ & 0.231 \\
\hline Platelets $\left[10^{3} / \mathrm{mm}^{3}\right]$ & $222 \pm 67$ & $231 \pm 76$ & $217 \pm 63$ & 0.230 \\
\hline PT-INR & $1.0 \pm 0.1$ & $1.0 \pm 0.1$ & $1.0 \pm 0.1$ & 0.785 \\
\hline Final ACT & $244.4 \pm 65.2$ & $250.8 \pm 67.2$ & $241.4 \pm 64.2$ & 0.378 \\
\hline \multicolumn{5}{|l|}{ Reasons for CAG } \\
\hline Investigation for $C A D$ & $163(95.3 \%)$ & $52(94.5 \%)$ & $111(95.7 \%)$ & 0.741 \\
\hline Valvular heart disease & $8(4.7 \%)$ & $3(5.5 \%)$ & $5(4.3 \%)$ & 0.741 \\
\hline \multicolumn{5}{|c|}{ Periprocedural anti-thrombotic medication } \\
\hline ASA loading & $69(40.4 \%)$ & $22(40.0 \%)$ & $47(40.4 \%)$ & 0.949 \\
\hline Clopidogrel loading & $90(52.6 \%)$ & $34(61.8 \%)$ & $56(48.3 \%)$ & 0.105 \\
\hline ASA & $162(94.7 \%)$ & $49(89.1 \%)$ & $113(97.4 \%)$ & 0.056 \\
\hline
\end{tabular}


Table 1 (cont.). Baseline clinical characteristics of the study population.

\begin{tabular}{lcccc}
\hline Patients & Total $(\mathbf{n}=\mathbf{1 7 1})$ & $\mathbf{4} \mathbf{F r}(\mathbf{n}=\mathbf{5 5})$ & $\mathbf{5} \mathbf{F r}(\mathbf{n}=\mathbf{1 1 6})$ & $\mathbf{P}$ \\
\hline P2Y12 inhibitor: & $159(93.0 \%)$ & $49(89.1 \%)$ & $110(94.8 \%)$ & 0.293 \\
Clopidogrel & $153(89.5 \%)$ & $48(87.3 \%)$ & $105(90.5 \%)$ & \\
Ticagrelor & $6(3.5 \%)$ & $1(1.8 \%)$ & $5(4.3 \%)$ & 0.799 \\
Oral anticoagulation & $14(8.2 \%)$ & $4(7.3 \%)$ & $10(8.6 \%)$ & $116(100 \%)$ \\
UFH or LMWH injection & $171(100 \%)$ & $55(100 \%)$ & \\
\hline
\end{tabular}

Values are presented as mean \pm standard deviation or as number (\%). ACT — activated clotting time; ASA — acetylsalicylic acid; CAD — coronary artery disease; CAG — coronary angiography; CKD — chronic kidney disease; DBP — diastolic blood pressure; eGFR — estimated glomerular filtration rate; LMWH — low molecular weight heparin; PT-INR — prothrombin time-international normalized ratio; SBP — systolic blood pressure; UFH - unfractionated heparin

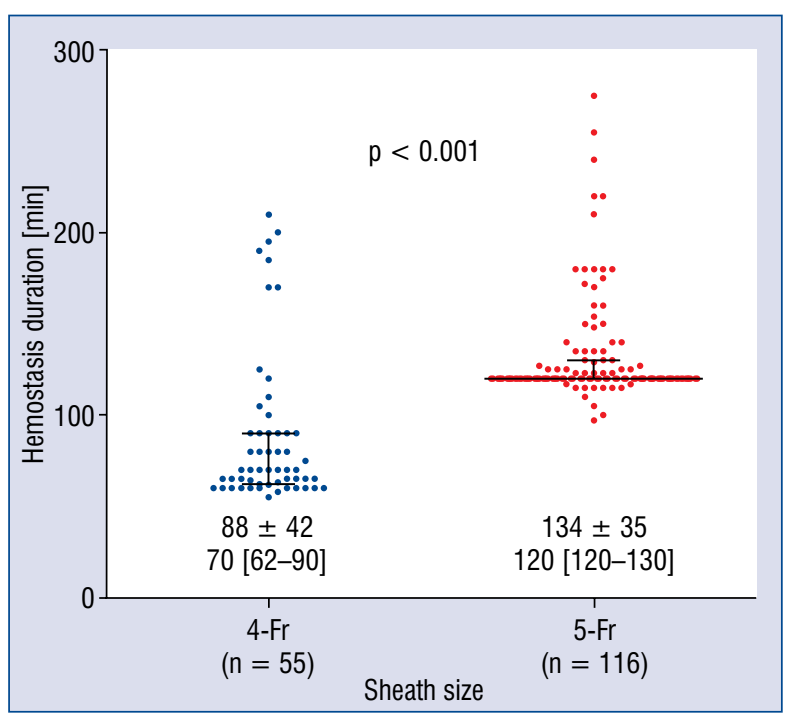

Figure 2. Hemostasis duration during the snuffbox approach according to sheath size.
5-Fr sheath groups, respectively. Moreover, there were no conventional and distal radial artery occlusions in any of the patients during hospitalization. According to available research, this is the first study reporting hemostasis duration during the snuffbox approach according to sheath size.

Although several studies have reported that $3 \mathrm{~h}$ could be enough to achieve successful hemostasis with the compressive bandage method or using a radial compression device, they did not suggest an optimal hemostasis duration according to sheath size, in PCI or in CAG [7-9]. Conversely, the current study revealed common hemostasis duration used in patients who underwent diagnostic CAG using a 4 -Fr or 5-Fr sheath. Despite the relatively short hemostasis durations ( $1 \mathrm{~h}$ with 4 -Fr and $2 \mathrm{~h}$ with 5-Fr sheaths), successful hemostasis, without access-site complications, was achieved in most patients; local hematoma (EASY classification I) oc-

Table 2. Snuffbox characteristics and puncture site complications.

\begin{tabular}{lcccc}
\hline Patients & Total $(\mathbf{n}=\mathbf{1 7 1})$ & $\mathbf{4} \mathrm{Fr}(\mathbf{n}=\mathbf{5 5})$ & $\mathbf{5 ~ F r}(\mathbf{n}=\mathbf{1 1 6})$ & $\mathbf{P}$ \\
\hline $\begin{array}{l}\text { Snuffbox approach details } \\
\text { Puncture time }\end{array}$ & & & & \\
$\quad$ Mean [s] & $145.1 \pm 120.8$ & $161.2 \pm 148.3$ & $137.4 \pm 105.1$ & 0.288 \\
$\quad$ Median [s] & $104[77.5-163]$ & $105[84.5-176]$ & $104[72-152]$ & 0.371 \\
Left snuffbox approach & $146(85.4 \%)$ & $51(92.7 \%)$ & $95(81.9 \%)$ & 0.101 \\
Hemostasis duration & $118.4 \pm 40.0$ & $88.4 \pm 42.0$ & $134.0 \pm 35.2$ & $<0.001$ \\
$\quad$ Mean [min] & $120[93.5-125]$ & $70[62-90]$ & $120[120-130]$ & $<0.001$ \\
$\quad$ Median [min] & $0(0 \%)$ & $0(0 \%)$ & $0(0 \%)$ & \\
Puncture site complications & $0(0 \%)$ & $0(0 \%)$ & $0(0 \%)$ & \\
Conventional RA occlusion & $0(0 \%)$ & $0(0 \%)$ & $0(0 \%)$ & \\
Distal RA occlusion & $8(4.7 \%)$ & $3(5.5 \%)$ & $5(4.3 \%)$ & 0.934 \\
Local numbness & & & \\
Local hematoma & &
\end{tabular}

Values are presented as mean \pm standard deviation or as number (\%). RA — radial artery 
curred in only $4.7 \%$ of the study population. Therefore, diagnostic CAG via the snuffbox approach, using a small size sheath, would be beneficial for patients who require an earlier discharge to return to their daily activities.

There were no conventional radial artery occlusions observed in the present study. Although there is concern that the sheath inserted through the snuffbox approach could damage the conventional radial artery, several studies demonstrated that no conventional radial artery occlusion was observed with successful hemostasis [7-10]. Hemostatic compression after conventional radial approach can lead to blood flow interruption in the conventional radial artery; the absence of blood flow during hemostasis was a potent predictor of conventional radial artery occlusion $[18,19]$. Thus, the snuffbox approach could be useful to preserve an access route in patients who may have a repeat coronary catheterization. In addition, the present study suggests that the snuffbox approach may be appropriate in providing an alternative access route in patients with chronic kidney disease who need to preserve their radial artery for the creation of an arteriovenous fistula in the future. However, a further prospective study is needed to confirm the patency of the conventional radial artery after the snuffbox approach using functional and imaging assessment.

\section{Limitations of the study}

This study has several limitations. First, this study has the inherent limitations associated with retrospective studies with small sample sizes. Second, the hemostasis duration after the snuffbox approach was evaluated without a control group. Therefore, the presented results should only be regarded as hypothesis generating. Third, although a reduction in the risk of conventional and distal radial artery occlusion is a potential benefit of the snuffbox approach, the occurrence of radial artery occlusion was evaluated only by manual pulse, without vascular ultrasonography. Furthermore, the patency of both radial arteries was not evaluated after discharge. These limitations could lead to an underestimation of access-site complications such as pseudoaneurysm or delayed radial artery occlusion.

\section{Conclusions}

Successful hemostasis was obtained within $2 \mathrm{~h}$ for diagnostic CAG via the snuffbox approach using the 4 -Fr or 5 -Fr sheaths. Further, large randomized control trials are needed to confirm the ideal hemostasis duration and the safety of the snuffbox approach in CAG and even PCI.

\section{Acknowledgements}

This work was supported by a grant from Chonnam National University Hospital Biomedical Research Institute (BCRI19009 \& BCRI8015).

\section{Conflict of interest: None declared}

\section{References}

1. Ferrante G, Rao SV, Jüni P, et al. Radial versus femoral access for coronary interventions across the entire spectrum of patients with coronary artery disease: a meta-analysis of randomized trials. JACC Cardiovasc Interv. 2016; 9(14): 1419-1434, doi: 10.1016/j.jcin.2016.04.014, indexed in Pubmed: 27372195.

2. Jolly SS, Yusuf S, Cairns J, et al. Radial versus femoral access for coronary angiography and intervention in patients with acute coronary syndromes (RIVAL): a randomised, parallel group, multicentre trial. Lancet. 2011; 377(9775): 1409-1420, doi: 10.1016/ S0140-6736(11)60404-2, indexed in Pubmed: 21470671.

3. Valgimigli M, Gagnor A, Calabró P, et al. Radial versus femoral access in patients with acute coronary syndromes undergoing invasive management: a randomised multicentre trial. Lancet. 2015; 385(9986): 2465-2476, doi: 10.1016/S0140-6736(15)60292-6, indexed in Pubmed: 25791214.

4. Neumann FJ, Sousa-Uva M, Ahlsson A, et al. ESC Scientific Document Group, ESC Scientific Document Group . Considerations for the choice between coronary artery bypass grafting and percutaneous coronary intervention as revascularization strategies in major categories of patients with stable multivessel coronary artery disease: an accompanying article of the task force of the $2018 \mathrm{ESC} / \mathrm{EACTS}$ guidelines on myocardial revascularization. Eur Heart J. 2019; 40(2): 204-212, doi: 10.1093/eurheartj/ ehy532, indexed in Pubmed: 30165435.

5. Rashid M, Kwok CS, Pancholy S, et al. Radial artery occlusion after transradial interventions: A systematic review and meta-analysis. J Am Heart Assoc. 2016; 5(1), doi: 10.1161/ JAHA.115.002686, indexed in Pubmed: 26811162.

6. Dandekar VK, Vidovich MI, Shroff AR. Complications of transradial catheterization. Cardiovasc Revasc Med. 2012; 13(1): 39-50, doi: 10.1016/j.carrev.2011.08.005, indexed in Pubmed: 22115936.

7. Kiemeneij F. Left distal transradial access in the anatomical snuffbox for coronary angiography (ldTRA) and interventions (ldTRI). EuroIntervention. 2017; 13(7): 851-857, doi: 10.4244/ EIJ-D-17-00079, indexed in Pubmed: 28506941.

8. Lee JW, Park SW, Son JW, et al. Real-world experience of the left distal transradial approach for coronary angiography and percutaneous coronary intervention: a prospective observational study (LeDRA). EuroIntervention. 2018; 14(9): e995-e99e1003, doi: 10.4244/EIJ-D-18-00635, indexed in Pubmed: 30222122.

9. Ziakas A, Koutouzis M, Didagelos M, et al. Right arm distal transradial (snuffbox) access for coronary catheterization: Initial experience. Hellenic J Cardiol. 2018 [Epub ahead of print], doi: 10.1016/j.hjc.2018.10.008, indexed in Pubmed: 30389385.

10. Soydan E, Akın M. Coronary angiography using the left distal radial approach - An alternative site to conventional radial coronary angiography. Anatol J Cardiol. 2018; 19(4): 243-248, doi: 10.14744/AnatolJCardiol.2018.59932, indexed in Pubmed: 29578203.

11. Kim Y, Ahn Y, Kim MC, et al. Gender differences in the distal radial artery diameter for the snuffbox approach. Cardiol J. 2018; 
25(5): 639-641, doi: 10.5603/CJ.2018.0128, indexed in Pubmed: 30394514.

12. Berezhnoi K, Kokov L, Vanyukov A, et al. Complete revascularization via left snuffbox approach in a nonagenarian patient with acute myocardial infarction. Cardiol J. 2018; 25(4): 530-531, doi: 10.5603/CJ.2018.0083, indexed in Pubmed: 30211930.

13. Kim Y, Jeong MH, Kim MC, et al. Successful primary percutaneous coronary intervention in patient with ST-segment elevation myocardial infarction via left snuffbox approach: Patient advantages. Cardiol J. 2019; 26(2): 198-199, doi: 10.5603/CJ.2019.0042, indexed in Pubmed: 31032871.

14. Kim Y, Jeong MH, Kim MC, et al. Successful percutaneous coronary intervention in patients with recanalized thrombus: Saving a radial artery by snuffbox approach. Cardiol J. 2019; 26(3): 292-293, doi: 10.5603/CJ.2019.0057, indexed in Pubmed: 31246265.

15. Kim Y, Ahn Y, Kim I, et al. Feasibility of Coronary Angiography and Percutaneous Coronary Intervention via Left Snuffbox Ap- proach. Korean Circ J. 2018; 48(12): 1120-1130, doi: 10.4070/ kcj.2018.0181.

16. Vefali V, Saricam E. The comparison of traditional radial access and novel distal radial access for cardiac catheterization. Cardiovasc Revasc Med. 2019; [Epub ahead of print].

17. Rao SV, Bernat I, Bertrand OF. Remaining challenges and opportunities for improvement in percutaneous transradial coronary procedures. Eur Heart J. 2012; 33(20): 2521-2526, doi: 10.1093/ /eurheartj/ehs169.

18. Sanmartin M, Gomez M, Rumoroso JR, et al. Interruption of blood flow during compression and radial artery occlusion after transradial catheterization. Catheter Cardiovasc Interv. 2007; 70(2): 185-189, doi: 10.1002/ccd.21058, indexed in Pubmed: 17203470.

19. Pancholy SB, Patel TM. Effect of duration of hemostatic compression on radial artery occlusion after transradial access. Catheter Cardiovasc Interv. 2012; 79(1): 78-81, doi: 10.1002/ ccd.22963, indexed in Pubmed: 21584923. 